\title{
O dISCURSO E A MEMÓRIA DO DIZER: O LUGAR DA INTERPRETAÇÃO
}

\author{
Ivanir Guidini Bana \\ Professora aposentada de Antropologia da UEL, \\ Mestre em Ciências Sociais/UEL
}

\section{Resumo}

A Análise do Discurso (AD) nos termos propostos por Michel Pêcheux tem como projeto fundamental o de estabelecer o processo discursivo como um produto material de relações internas e externas, isto é, a base lingüística e a determinação ideológica respectivamente. O presente trabalho tem o objetivo de mostrar como a problemática da determinação do sentido e da constituição ideológica do sujeito na linguagem é tratada pela $\mathrm{AD}$ na tentativa de construir uma metodologia de análise que aborda a prática discursiva num âmbito interdisciplinar.

Palavras-chave: análise de discurso, sentidos, silêncio.

[...] o que aparece, mas nós só poderemos evocar abusivamente, é como, em um discurso dado, para um enunciador dado, a escolha feita nesta variedade - quais figuras são escolhidas preferencialmente, e mesmo qual figura exclusivamente, até as vezes no tique? - colore de forma singular essa música - ou esse barulho - do silêncio reencontrado no dizer que, sob modos quantitativamente bastante diferentes, os de uma música ocasional, leve, ou insistente, lancinante, que se esvai, acompanha o fio 'principal' de um discurso. (J. AUTHIER-REVUZ)

Análise do Discurso (AD) de vertente francesa inspirada em Michel Pêcheux mostra que a linguagem não é apenas uma questão que concerne à língua, levando-nos a ter contato com determinações de natureza heterogênea, dirigindo-nos para enunciações históricas, sociais e ideológicas relevantes. 
A $\mathrm{AD}$ trabalha com a materialidade da linguagem levando em conta o lingüístico e o histórico, dimensões indissociáveis no processo de produção do sujeito do discurso e dos sentidos que o significam.

Já que o homem histórico é o homem que vive, que trabalha e que fala, todo conteúdo da história, qualquer que seja vem da psicologia, da sociologia e das ciências da linguagem. Mas inversamente, visto que o ser humano se tornou de um lado e de outro histórico, nenhum dos conteúdos analisados pelas ciências humanas pode permanecer em si mesmo estável nem escapar ao movimento da História. (FOUCAULT apud HENRY, 1997, p.42)

Ao estabelecer uma crítica ao objetivismo abstrato que advoga a autonomia da língua e ao subjetivismo idealista, no qual domina a onipotência do sujeito e da fala, a $\mathrm{AD}$ assume uma posição de pensar um objeto ao mesmo tempo social e histórico em que se confrontam sujeito e sistema, isto é, o discurso.

Se, de um lado, a relação com a linguagem não é uma relação com evidências e se situa em face da articulação do simbólico com o político, por outro lado, o sujeito discursivo não realiza apenas atos. Ao dizer, concomitantemente, ele significa e significa o próprio mundo. Nesse sentido, a linguagem é uma prática não porque efetua atos, mas porque pratica sentidos, isto é, intervém no real. O sentido é história de modo que o sujeito se significa na e pela história. Por sua vez, as palavras não estão ligadas às coisas diretamente, nem são os reflexos de uma evidência. A relação entre palavra e coisa é tornada possível pela ideologia e, desse modo, a ideologia reúne sujeito e sentido.

O fato de que há uma distinção entre língua e ideologia enquanto componentes que se articulam imbricadamente no discurso, é que leva Pêcheux a realizar uma advertência contra a tendência de assimilar a língua a uma superestrutura ideológica, na qual o aspecto lingüístico do processo discursivo perderia sua especificidade.

Isso nos leva a questionar sobre que tipo de tratamento analítico se pode dar a um corpus discursivo na etapa de análise que Pêcheux (1997) chama de fase lingüística. A primeira precaução teórica do autor é a de separar o que ele denomina uma semântica discursiva e uma semântica lingüística. A semântica lingüística deveria consistir numa 
teoria ainda por elaborar e que desse conta do funcionamento material da língua em relação a si própria:

Apresentada em sua forma extrema, a posição lingüística inerente à $\mathrm{AAD}$ voltaria a considerar que sintaxe e semântica constituem dois níveis autônomos e bem definidos e que léxico e gramática são igualmente dois domínios distintos. Ora, visivelmente, isto não é assim. Aliás, a fase lingüística da $\mathrm{AAD}$ em seu estado atual ilustra bem as dificuldades ligadas a semelhante exigência: longe de evitar qualquer contaminação da análise lingüística pela semântica, as regras sintáticas aplicadas introduzem sub-repticiamente recursos não-controlados ao sentido. Quer dizer que esta semântica à qual a análise sintática não pode deixar de recorrer é precisamente o que foi designado acima sob o nome de semântica discursiva? Se assim o fosse, isto equivaleria a dizer que a autonomia teórica da lingüística é praticamente nula já que só se reencontraria no fim o que tivesse sido colocado no início. Não creio que isto seja assim. Essa situação nos parece de fato ligada a herança filosófica que as categorias gramaticais veiculam necessariamente, mesmo sob seus aspectos mais neutro, mais moderno, mais técnico. O que falta atualmente é uma teoria do funcionamento material da língua em sua relação consigo própria, isto é, uma sistematicidade que não se opõe ao não-sistemático (línguas/fala), mas que se articula em processos (PÊCHEUX, 1997, p.173).

Portanto, segundo Pêcheux, elaborada essa teoria semântica linguística, a $\mathrm{AD}$ poderia localizar em que plano se realiza, na língua, a sua passagem pela constituição do efeito sujeito. O importante, para o autor, é, no procedimento de análise discursiva, ter o cuidado de não reproduzir e de não esquecer a existência desse efeito-sujeito no objeto de análise.

A enunciação é um conceito básico a ser incluído no corpo teórico e metodológico da $\mathrm{AD}$. Pêcheux rejeita as perspectivas idealistas acerca dessa instância de linguagem. Questiona a concepção de Benveniste ${ }^{1}$ de enunciação, isto é, a idéia de que esta designa o ato individual de utilização da língua. Esta definição reflete a ilusão de que o sujeito é a fonte de seus enunciados ou do sentido contido neles.

'Pêcheux (1997) quando discute a distinção que Benveniste realiza entre "Discurso" e "História". 
Para Pêcheux essa concepção cria obstáculos como a ilusão empirista subjetiva e a ilusão formalista que reduz o fato enunciativo a um simples sistema de operações. A esta reflexão crítica, este autor incorpora as ponderações de Hisbrunner e Fiala, deparando-se aqui com o paradoxo do fato de que, em rejeitando o conceito de língua como sistema (a langue) para ressaltar a sua contraparte não-sistemática (a parole), a teoria lingüística acaba reintroduzindo noções empiristas anteriormente repelidas como condição para que a lingüística se constituísse como ciência. Estas noções nos remetem ao problema do sujeito e a sua relação com o mundo social:

Certamente, o conceito de língua concebido apenas como sistema de signos é ultrapassado, mas ao custo da introdução, no seio mesmo da teoria lingüística, das duas noções que havia tentado rejeitar, o sujeito e sua relação com o mundo social. Ora - e aí está o paradoxo - estas duas noções, se elas vêm preencher um espaço no aparelho conceptual, não tem de fato, nenhum estatuto teórico preciso. Opondo a liberdade do sujeito individual à necessidade do sistema da língua, colocando a língua como mediação entre o sujeito e o mundo, e o sujeito como se apropriando do mundo por intermédio da língua, e da língua por intermédio do aparelho de enunciação. Benveniste apenas transpõe em termos lingüísticos noções filosóficas que, longe de serem neutras, se ligam diretamente à corrente idealista. (HISBRUNNER; FIALA apud PÊCHEUX; FUCHS, 1997, p.175)

A questão das teorias de enunciação, realizadas não só por Benveniste, mas também por Jakobson e outros, liga-se ao fato de elas adotarem teoricamente a ilusão de um sujeito enunciante dotado de intenções, escolhas e decisões.

Fica claro nas críticas levantadas aos empiristas que a busca das marcas lingüísticas da subjetividade em si, que seria o reflexo de uma evidência perceptível, psicológica, isto é, um sujeito livre em suas escolhas, não proporciona a problematização das determinações sociais e ideológicas do sujeito falante na linguagem.

Existem outras abordagens que vão conceber de maneira diferente a noção do sujeito. Brandão (1991) aponta algumas em que a noção de história é fundamental e o sujeito é essencialmente histórico: 
É porque sua fala é produzida a partir de um determinado lugar e de um determinado tempo, à concepção de um sujeito histórico articula-se outra noção fundamental: a de um sujeito ideológico. Sua fala é um recorte das representações de um tempo histórico e de um espaço social. Dessa forma, como ser projetado num espaço e num tempo orientado socialmente, o sujeito situa o seu discurso em relação aos discursos do outro. Outro que envolve não só o seu destinatário para quem planeja, ajusta sua fala (nível intradiscursivo), mas que também envolve outros discursos historicamente já constituídos e que emergem na sua fala (nível interdiscursivo), (BRANDÃO, 1991, p.49).

É baseado nesta via epistemológica que Pêcheux vai buscar na Psicanálise os mecanismos de representação que constituem o sujeito na linguagem. Para descrever as séries de determinações que cruzam a forma-sujeito desde o plano ideológico até o plano da enunciação lingüística, o autor faz uso dos conceitos teóricos construídos por Freud e retomados por Lacan ${ }^{2}$. Assim, no sistema inconsciente, o sujeito "esquece" as determinações que o constituem, enquanto tal. $\mathrm{Na}$ verdade, não se trata de "esquecer" no sentido estrito. Como explica Pêcheux (1997), é como se o sujeito nunca soubesse das determinações ideológicas que o precedem. Isso se passa no processo discursivo no momento em que os elementos de uma formação discursiva desprendem-se para outro oponente na constituição de uma formação discursiva dominante. Aqui, uma formação discursiva precedente é tomada como a representação primária de que se serve o sujeito, sem o saber, para construção de uma segunda formação discursiva, a que deverá ser tomada ideologicamente como dominante num contexto his-

\footnotetext{
${ }^{2}$ Freud, ao distinguir as regiões na estrutura do psiquismo, quais sejam: a consciente, a pré-consciente e a inconsciente, concentra esta última como a região que incluiria todos os processos e representações voluntariamente inacessíveis à evocação, embora permeáveis à análise. Em Lacan, prevalece uma noção sob o ângulo da lingüística, em que o inconsciente é entendido como uma linguagem. Para ele, todo nosso sistema psíquico é organizado segundo uma linguagem. Ao procurar detectar a estrutura de transformação dos símbolos do inconsciente individual em uma linguagem consciente e social, considera possível estudá-los (os símbolos) através do modelo racional de nossa linguagem. Optamos por não aprofundar esta discussão da noção do inconsciente nos autores por não se constituírem objetos específicos de análise em nosso trabalho.
} 
tórico dado. Isso acontece através de um mecanismo fora da consciência do sujeito falante. Esse processo distingue o que Pêcheux denomina esquecimento número 1 e seu caráter é o de construir o sujeito ideológico, a figura do locutor que responde pelos seus enunciados.

[...] a noção de 'ato de linguagem' traduz, de fato, o desconhecimento da determinação do sujeito no discurso. Permite, ainda, dizer que, na verdade, a tomada de posição não é, de modo algum, concebível como um 'ato originário' do sujeito falando: ela deve ao contrário, ser compreendida, como o efeito, na forma sujeito, da determinação do interdiscurso como discursotransverso, isto é, o efeito da 'exterioridade' do real ideológico discursivo, na medida em que ela 'se volta sobre si mesma' para se atravessar. Nessas condições, a tomada de posição resulta de um retorno do 'sujeito' no sujeito, de modo que a não-coincidência subjetiva que caracteriza a dualidade sujeito/objeto, pela qual o sujeito se separa daquilo que ele 'toma consciência' e a propósito do que ele toma posição, é fundamentalmente homogênea à coincidência-reconhecimento pela qual o sujeito se identifica consigo mesmo, com seus 'semelhantes' e com o 'sujeito'. O 'desdobramento' do sujeito como 'tomada de consciência' de seus 'objetos' - é uma reduplicação da identificação, precisamente na medida em que ele designa o engodo dessa impossível construção da exterioridade no próprio interior do sujeito (PÊCHEUX, 1997, p.172).

São essas considerações de caráter psicanalítico que evidenciam a reflexão de que as posições assumidas pelo sujeito no discurso não têm origem nele mesmo, ou seja, não são resultado de uma mesma intenção consciente atuando no sujeito falante.

Pêcheux vai opor ao esquecimento número 1 a forma de esquecimento número 2. Esta última, ao contrário da primeira, sendo de natureza pré-consciente, é passível de chegar à consciência do sujeito. Este tipo de esquecimento designa o processo pelo qual se realiza no sujeito falante a seleção, no interior de um conjunto de enunciados, daqueles que devem compor o sentido de seu discurso segundo uma dada informação ideológica que o precede sob a forma de esquecimento número 1 : o esquecimento número 2 cobre exatamente o funcionamento do sujeito do discurso na formação discursiva que 0 
domina, e que é aí, precisamente, que se apóia sua 'liberdade' de sujeito falante (PÊCHEUX, 1997, p.175).

Este processo subjetivo que se dá em nível pré-consciente caracteriza o fenômeno de produção de representações verbais no interior de um discurso dado a partir de outras representações preexistentes. Este é o ponto localizado entre o dito e o não-dito do processo de enunciação.

É assim que Pêcheux estabelece que a possibilidade de conscientização aqui se sucede de uma forma contínua e acontece quando o falante se volta, se concentra em sua própria fala, retificando, ratificando o que está dizendo e antecipando o efeito de seu discurso.

Os trabalhos teóricos filiados à linha de reflexão fundada por Pêcheux pressupõem o descentramento do sujeito e a historização do sentido. Logo, o sujeito não é mais entendido como origem e fonte do dizer em absoluto controle estratégico e intencional do sentido de "seus" enunciados. Pelo contrário, assume-se a determinação ideológica do sujeito por formações discursivas que o precedem e excedem, dentro das quais se constituem as diferentes posições do sujeito, permitindo-lhe sua enunciação. A mesma determinação ideológica opera sobre o sentido, o qual não está na língua nem no sujeito (como fruto de um planejamento estratégico a partir de uma intenção de comunicação). Contrariamente, o sentido é produzido materialmente a partir dos processos discursivos que delimitam/opõem as formações discursivas que atravessam uma formação social.

Deste modo, sujeito e sentido se constituem mutuamente em relação a uma ou a várias formações discursivas, dentro das quais os dois são produzidos como efeitos - efeitos de sentido e efeito sujeito.

É assim que as formações discursivas funcionam como fonte para produção do sentido e elas determinam o que pode e deve ser dito a partir de uma posição dada numa conjuntura histórica determinante (PÊCHEUX, 1997). As relações de paráfrase ${ }^{3}$ anteriores à fonte (ou matriz) de sentido inerente a uma formação discursiva se constituem em processos discursivos.

\footnotetext{
${ }^{3}$ Definimos segundo Orlandi (1999, p.36): "Os processos parafrásticos são aqueles pelos quais em todo dizer há algo que se mantém, isto é, o dizível, a memória. A paráfrase representa assim o retorno aos mesmos espaços do dizer. Produzem-se diferentes formulações do mesmo dizer sedimentado".
} 
É com esse significado que a produção do sentido é indissociável destas relações de paráfrase entre seqüências diferentes pertencentes a uma mesma formação discursiva.

Portanto, os processos discursivos não têm origem no sujeito, mas se inscrevem fundamentalmente nele através de uma relação de identificação do sujeito enunciador com o sujeito universal ou forma sujeito $^{4}$ de una formação discursiva.

A relação de identificação que constitui o sujeito enunciador em sujeito ideológico é nomeada posição de sujeito. Diferentes posições de sujeito são fixadas por diferentes sujeitos relacionando-se com a formasujeito de uma mesma formação ideológica. Como resultado, são produzidos diferentes efeitos-sujeito no interior do discurso de cada sujeito.

Quando a enunciação é definida como uma relação necessariamente presente do sujeito enunciador com o seu enunciado, aparece reproduzida no nível teórico a ilusão subjetiva que constitui o sujeito como ego-imaginário. Em outras palavras, ao definir enunciação como a organização do discurso do sujeito enunciador com o seu enunciado (típico das abordagens não discursivas) aparece reproduzida em nível teórico a ilusão subjetiva que constitui o sujeito como ego-imaginário.

Assim, definir enunciação como organização do discurso do sujeito enunciador por referência direta ou divergente, ou por ausência de referência, à situação de enunciação (o eu-aqui-agora do locutor) é resultado do apagamento teórico da determinação ideológica que afeta tanto o sentido do enunciado quanto o próprio sujeito enunciador. Ainda que esse apagamento seja constitutivo da atividade da linguagem, isto é, da relação que o sujeito enunciador estabelece com o ato de enunciação, ele não deve ser refletido no nível teórico.

Portanto, a Análise do Discurso descreve a enunciação, em relação ao sujeito enunciador, como os mecanismos imaginários apoiados em diversas formas da língua, constituindo-o como ego-imaginário e indivíduo de uma vontade comunicativa.

\footnotetext{
${ }^{4}$ A definição de forma-sujeito foi proposta por Althusser e reproduzida por Pêcheux (1997). "Todo indivíduo humano, isto é, social, só pode ser agente de uma prática se revestir-se da forma de um sujeito. A forma-sujeito, de fato é forma da existência histórica de qualquer indivíduo, agente das práticas sociais".
} 
Somos, assim, levados a examinar as propriedades discursivas da forma-sujeito, do 'ego-imaginário', como 'sujeito do discurso'. Já observamos que o sujeito se constitui pelo 'esquecimento' daquilo que o determina. Podemos agora precisar que a interpelação do indivíduo em sujeito de seu discurso se efetua pela identificação (do sujeito) com a formação discursiva que o domina (isto é, na qual ele é constituído como sujeito): essa identificação, fundadora da unidade (imaginária) do sujeito, apóiase no fato de que os elementos do interdiscurso (sob sua dupla forma, enquanto 'pré-construído' e 'processo de sustentação') que constituem, no discurso do sujeito, os traços daquilo que o determina, são re-inscritos no discurso do próprio sujeito (PÊCHEUX, 1997a, p.163).

Assim, essa representação do sujeito enunciador não é mais do que uma ilusão produzida como resultado (como já mostramos acima) de um duplo esquecimento.

De um lado temos o esquecimento número 1 por meio do qual fica recalcada para o sujeito sua inscrição numa formação discursiva, com cuja forma-sujeito ele se identifica e a partir do qual ele enuncia. $\mathrm{O}$ fruto deste esquecimento é a ilusão subjetiva de estar na origem dos enunciadores. $\mathrm{O}$ esquecimento funciona no nível do inconsciente do sujeito e os processos discursivos que formam o seu discurso conservam-se inacessíveis para o sujeito enunciador.

Por outro lado, o esquecimento número 2 através do qual o sujeito tem a ilusão da realidade do seu pensamento (de que o dito só pode ser dito como ele disse) funciona no nível consciente ou préconsciente, fato que permite ao sujeito enunciador ter um certo acesso às operações de argumentação e organização textual do "seu" discurso. Tais operações se representam imaginariamente para o sujeito da enunciação como uma "tomada de posição" em relação ao enunciado. Esta "tomada de posição" é, na verdade, imaginária, já que o sujeito enunciador só tem acesso às operações que constroem as formulações e não aos enunciadores do "seu" discurso. Em outras palavras, o sujeito só opera conscientemente com o "dito" e no dizível, menos com o que fica fora deste dizível.

Observa-se que a exterioridade não determina uma subjetividade empírica fora da linguagem, ao contrário, é uma exterioridade que 
intervém materialmente na textualidade como interdiscurso, memória do dizer que abrange o universo do dizível.

[...] a exterioridade não tem objetividade empírica do 'fora' da linguagem, pois; na análise de discurso, a exterioridade é suprimida para intervir como tal na textualidade. E é isto que chamamos discursividade. Trata-se, portanto, de pensar a exterioridade discursiva. A noção que trabalha a exterioridade discursiva (ou interioridade discursiva) é a de interdiscurso. E o que define o interdiscurso é sua objetividade material contraditória, objetividade material essa que, [...] reside no fato de que algo fala sempre antes, em outro lugar e independentemente, isto é, sob a dominação do complexo das formações ideológicas. É isto que fornece "a cada sujeito" a sua "realidade" enquanto sistemas de evidências e de significações percebidas - aceitas - experimentadas. É aí que se explicita o processo de constituição do discurso: a memória, o domínio do saber, os outros dizeres já ditos ou possíveis que garantem a formulação (presentificação) do dizer, sua sustentação. Garantia de legibilidade e de interpretação: para que nossas palavras façam um sentido é preciso que (já) signifiquem. Essa impessoabilidade do sentido, sua impressão referencial, resulta do efeito de exterioridade: o sentido lá. A objetividade material contraditória. O efeito de exterioridade, por sua vez, é que compõe, ou torna possível, a nosso ver, a relação discursiva real/realidade. Tendo o real, a função das determinações históricas que constituem as condições de produções materiais e a realidade a relação imaginária dos sujeitos com essas determinações, tal como elas se apresentam no discurso, ou seja, num processo de significação para o sujeito, constituído (ideologicamente) pelos esquecimentos: o que resulta na sensação do sujeito como origem e a que produz a impressão da realidade do pensamento (ORLANDI, 1996, p.38).

Enfim, a enunciação é vista historicamente, a significação é histórica na medida em que é determinada pelas condições sociais de sua existência. Sua materialidade é esta historicidade. O sentido deve ser tratado como discursivo e definido a partir do acontecimento enunciativo.

A questão do assujeitamento do sujeito continua provocando inúmeras discussões. Para Possenti (1996), essa questão apresenta dois extremos: os sujeitos livres e os sujeitos assujeitados. O autor propõe a inserção de sujeitos ativos contrapondo os sujeitos que se 
decidiram a seu bel-prazer e ao assujeitado, ponto pelo qual passariam discursos prévios.

Para o autor, a $\mathrm{AD}$ na tentativa exagerada de evitar o sujeito cartesiano $^{5}$, coloca em causa as certezas sobre o sujeito assujeitado. Assim, seria necessário levantar questões sobre se a descoberta do inconsciente recusa, essencialmente, qualquer manobra consciente dos sujeitos, se o sujeito precisa saber o que é para saber o que diz, se a existência de condições anula qualquer opção de sujeitos.

Para tanto, Possenti (1996, p.41-43) postula alguns princípios:

1) Os sujeitos são integralmente sociais e históricos e integralmente individuais - para evitar o subjetivismo e a identificação do sujeito como uma peça;

2) Cada discurso é integralmente histórico e social e integralmente pessoal e circunstancial - para evitar a idéia de que o sujeito é fonte de seu discurso e a de que é o discurso que se dá;

3) Cada discurso é integralmente interdiscursivo e integralmente relativo a um mundo exterior - para evitar a idéia de que $o$ discurso refere-se diretamente às coisas e a de que tudo é discurso ou que a realidade, se houver uma, é criada pelo discurso;

4) Cada discurso é integralmente ideológico e/ou consciente e integralmente cooperativo e interpessoal - para evitar a idéia de que o sujeito diz o que diz materializando as suas intenções e a de que o sujeito não tem nenhum poder de manobra e que o interlocutor concreto é irrelevante.;

5) O falante sabe (integralmente?) o que está dizendo e ilude-se (integralmente?) se pensar que sabe o que diz (ou que só diz o quer) - para evitar que se desconheçam os saberes que os sujeitos acumulam em sua prática histórica e que se conclua disso que nada lhes é estranho ou desconhecido.

Deste modo, para que o sujeito possa ser entendido como algo mais que um lugar por onde o discurso passa, vindo da estrutura, necessita-se estabelecer a hipótese mínima de que ele age.

O autor propõe uma teoria psicológica, "na qual o sujeito fosse 'clivado pelo inconsciente', mas não fosse reduzido a uma peça

${ }^{5}$ Entendemos que Possenti refere-se ao sujeito semi-inconsciente, não pertencente a uma classe e não ligado à ideologia. 
que apenas sofre efeitos. Certamente há domínios em que os sujeitos só sofrem efeitos, mas há outros em que uma atuação é demandada e verificável" (p.44). Concluindo seus questionamentos com a seguinte observação:

Se esta $\mathrm{AD}$ pode aceitar agora que os proletários têm um inconsciente, então quem sabe se possa fazer a suposição não ingênua, não positivista ou psicologista de que intelectuais ligados a teorias e epistemes, sujeitos que falam do interior de ideologias, ou formações discursivas, políticos que falam a partir de programas partidários, padres que professam sermões repetindo sua teologia, sindicalistas que fazem suas arengas, professores que dão aulas e mesmo (por que não ousar?) analistas do discurso tenham um cérebro e uma mente (p.46).

Impossível ignorar essas preciosas considerações de Possenti ${ }^{6}$, mesmo porque ao mesmo tempo que elas nos suscitam inquietações, sem dúvida apenas parcialmente resolvidas, elas nos remetem ao tratamento emergencial com que elas foram tratadas ao longo do percurso da $\mathrm{AD}$.

Brandão (1998) assinala esse movimento, mostrando que na linguagem o conceito de subjetividade passou por três momentos fundamentais:

Primeiro, a inaugurada por Benveniste, que através do estudo dos pronomes faz emergir a questão da subjetividade na linguagem, buscando a constituição do sujeito no interior do discurso que profere. Mesmo afirmando que o "eu" se constitui à medida que alguém vai sendo instituído como tu, é o Ego o centro da enunciação. $O$ autor reduz a ele a noção de sujeito ao afirmar que a constituição da subjetividade vai se fazendo à medida que vai tendo a capacidade de dizer "eu". $\mathrm{O}$ tu permanece figura complementar ao eu, a noção da subjetividade não é expandida para fora do eu (pessoa subjetiva) e ao tu (pessoa não subjetiva) não é atribuído um estatuto essencial de subjetividade.

O segundo momento é o formulado por Pêcheux, ao colocar o sujeito no quadro de uma formação ideológica e discursiva.

${ }^{6}$ A proposta de Possenti em relação ao sujeito pode ser aprofundada na obra: Possenti, Os limites dos discurso: ensaios sobre o discurso e o sujeito. Curitiba : Criar, 2002. 
Retomando Pêcheux é possível mostrar que na $\mathrm{AD} 1$ a noção de sujeito é determinada pela posição, pelo lugar de onde se fala. Isto se dá no interior de uma formação discursiva, regulada por uma ou mais formações ideológicas. É o sujeito assujeitado. Os sujeitos acreditam que 'utilizam' seus discursos quando na verdade são seus 'servos' assujeitados, seus 'suportes"' (PÊCHEUX, 1997, p.311).

$\mathrm{E}$, finalmente a partir da AD2 essa noção começa a ser desfeita com o reconhecimento de que a FD (Formação Discursiva) está em relação contraditória com seu "exterior". Ela é formada por outras FDs que vão se refletir nela. É aí que aparece a noção de interdiscurso, designando o exterior específico de uma FD que surge no interior desta FD. Então, mesmo conservando o conceito fechado de FD enquanto dispositivo estrutural, ao mesmo tempo ele é entendido como resultado paradoxal do surgimento de um 'além' exterior e anterior. $\mathrm{O}$ sujeito continua ainda sendo concebido como efeito de assujeitamento operando, num nível inconsciente ideológico, esquecimento número 1 e num nível pré-consciente ou consciente o esquecimento número 2:

Um sujeito que se desdobra em vários papéis segundo as várias posições que ocupa numa FD (que é atravessada por várias FDs) a ilusão discursiva da unidade, da origem, constitui uma 'ilusão necessária' para a manutenção da identidade. Identidade cujo fechamento é colocado em causa pelo reconhecimento da alteridade que irrompe no interior de um sujeito marcado pela dispersão das várias posições que assume no seu discurso. Vaise, assim, inaugurando uma fase cada vez mais dominada por uma preocupação nova, que vinha sendo gestada há tempo: a da heterogeneidade discursiva que leva PÊCHEUX a questionar a própria concepção de FD (BRANDÃO, 1998, p.41).

Com isso, conforme Pêcheux (1997), a AD3 aponta para a emergência de novos procedimentos da $A D$ através das maquinarias discursivas, ou seja,

[...] indicar algumas direções referiveis em um trabalho de interrogação-negação-desconstrução das noções postas em jogo na $\mathrm{AD}$, mostrar alguns fragmentos de construção nova: 
1) O primado teórico do outro sobre o mesmo se acentua, empurrando até o limite a crise da noção de máquina discursiva estrutural. É mesmo a condição de construção de novos algorítmos enquanto 'máquinas paradoxais'.

2) O procedimento da $A D$ por etapas, com ordem fixa, explode definitivamente através da desestabilização das garantias sócio-históricas que se supunham assegurar a priori a pertinência teórica de procedimentos de uma construção empírica do corpus refletindo essas garantias (PÊCHEUX, 1997, p.315).

Para Pêcheux, o desenvolvimento de novas pesquisas permite a AD3 "abordar o estudo da construção dos objetos discursivos e dos acontecimentos, e também dos 'pontos de vista' e 'lugares enunciativos no fio intradiscursivo'. Os desenvolvimentos teóricos que se aproximam da heterogeneidade enunciativa conduzem a tematização das formas lingüístico-discursivas do discurso-outro":

'Discurso de um outro colocado em cena pelo sujeito', ou discurso do sujeito se colocando em cena como um outro. Mas também e sobretudo a insistência de um 'além' interdiscursivo que vem, aquém de todo autocontrole funcional do 'ego eu', enunciador estratégico que coloca em cena 'sua' seqüência, estruturar esta encenação (nos pontos de identidade nos quais o 'ego-eu' se instala) ao mesmo tempo em que desestabiliza (nos pontos de deriva em que o sujeito passa no outro, onde o controle estratégico de seu discurso lhe escapa) (PÊCHEUX, 1997, p.317).

E, finalmente, entre os diversos pontos de interrogação de Pêcheux:

Como separar, nisso que continuamos a chamar o sujeito da enunciação, o registro funcional do 'ego-eu' estrategista assujeitado (o sujeito ativo intencional teorizado pela fenomenologia) e a emergência de uma posição do sujeito? Que relação paradoxal essa emergência mantêm com o obstáculo, a irrupção imprevista de um discurso-outro, a falha no controle? O sujeito seria aquele que surge por instantes, lá onde o 'ego-eu' vacila? Como inscrever as conseqüências de uma tal interrogação nos procedimentos concretos da análise? (PÊCHEUX, 1977, p.317). 
Para Brandão (1998), Pêcheux nas últimas fases de seu trabalho aproxima-se de Authier-Revus que recorre à Psicanálise, buscando as formas de constituição do sujeito na diversidade de uma fala heterogênea, conseqüência de um sujeito dividido entre o consciente e $o$ inconsciente.

Fundamentada em Freud, em que o eu perde sua centralidade, Authier-Revus tem analisado aquilo que ela denomina de heterogeneidade mostrada como formas de rupturas que interferem no fio do discurso e coloca em confronto a identidade/alteridade do sujeito. Essa heterogeneidade, apesar de não marcada na superfície, é possível de ser marcada pela relação que todo o discurso mantém com outros discursos.

[...] segundo AUTHIER-REVUS existe uma negociação entre a heterogeneidade mostrada na linguagem e a heterogeneidade constitutiva da linguagem em que o sujeito, movido pela ilusão do centro, pela ilusão de ser a fonte do discurso, por um processo de denegação, localiza o centro e delimita o seu lugar para circunscrever o próprio território. Afetado por um sujeito que divide, ou melhor, que tem que dividir seu espaço discursivo com o outro, o sentido se subjetivisa, torna-se heterogêneo, bloqueando a tendência natural à homogeneização do sentido absoluto (BRANDÃO, 1998, p.44-45).

Resta-nos, então, a certeza do "sentimento" - pelo menos até o momento em que esta questão vem sendo objeto da reflexão - de que se deve reconhecer o sujeito na sua complexa variedade, ou seja, nem completamente assujeitado nem totalmente livre.

Para nós, a orientação teórica da $\mathrm{AD}$ sobre o funcionamento do efeito de ilusão de exterioridade em relação às formas de representação do sujeito do discurso - uma posição de sujeito que funciona imaginariamente para o sujeito enunciador ${ }^{7}$ como um lugar externo e descentrado a partir do qual ele se representa como sendo um outro não se reveste em assujeitamento absoluto do sujeito.

${ }^{7}$ Definimos enunciação como um acontecimento de linguagem perpassado pelo interdiscurso, que se dá como espaço da memória no acontecimento (GUIMARÃES, 1993, p.28). 
Os argumentos de Ducrot (1992, p.13) na passagem em que ele discute a questão de sentido literal, podem contribuir para esta discussão.

1) que cada enunciado possui independentemente de toda enunciação, uma 'significação' que podemos, se quisermos chamar de 'sentido literal';

2) que essa 'significação' ('sentido literal') é mesmo um 'objeto de conhecimento' ('objeto' no sentido de Saussure, 'objeto específico' no sentido de Hjelmslev), e que ela não é nem uma parte do objeto real (isto é, do 'sentido das enunciações') nem uma entidade da mesma natureza, suscetível de ser visada por um ato de comunicação;

3) que ao se descrever o sentido de uma enunciação é importante distinguir aquilo que ela põe daquilo que ela pressupõe;

4) que essa distinção, mesmo quando acrescentada ao enunciado no momento da enunciação, pode já estar marcada no interior da significação;

5) que a língua, considerada como um conjunto de enunciados semanticamente caracterizados, revela-se um instrumento de ação [grifo nosso] antes de ser um instrumento de informação;

6) que é possível considerar o enunciador como 'sujeito' (isto é, como capaz de se representar, em um certo nível, o sentido daquilo que ele diz), sem que seja necessário para isso confundir esse sentido com a significação do enunciado, ou sentido literal.

Se, entretanto, não existe razão teórica para restringir o efeito de ilusão de exterioridade, é possível recorrer à idéia de que, mesmo que as chamadas formas de distanciamento ou apagamento do sujeito sejam os elementos da língua mais estudados em relação ao efeito de ilusão de exterioridade, eles não são os únicos através dos quais se manifesta este efeito ${ }^{8}$ : É possível incorporar a idéia de que elementos que comumente são descritos como marcas de subjetividade, isto é, como manifestação explícita da atividade enunciativa realizada pelo sujeito servem de base material para a produção de um efeito de ilusão de exterioridade para o sujeito do discurso.

\footnotetext{
${ }^{\S}$ Em relação ao sentido, a enunciação é definida "como processo de enunciação <que > consiste em uma série de determinações sucessivas pelas quais o enunciado se constitui pouco a pouco e que tem por característica colocar o "dito" e em conseqüência rejeitar o "não-dito" (PÊCHEUX; FUCHS, 1997, p.175-176).
} 
Porque o sentido não é um, são muitos, é que o sujeito discursivo deve ser pensado como itinerante. Isto está claro na Análise de Discurso quando define o dizível pelo conjunto de diferentes formações discursivas que se põem em jogo em cada gesto do dizer.

Orlandi (1996), seguindo essa linha de pensamento, forneceunos um outro e novo olhar sobre a linguagem e sobre o sentido através da consideração de que o silêncio é a própria condição da produção de sentido.

Para a autora o silêncio tem muitas formas, das quais são mais importantes:

1) o silêncio fundador, pelo qual afirmo que não há significação possível sem silêncio: é o silêncio que existe nas palavras, o que significa o não-dito e o que dá espaço de recuo significante produzindo as condições para significar;

2) a política do silêncio que se subdivide em:

b1) silêncio constitutivo ou anti-implícito, o que nos indica que para dizer é preciso não dizer (uma palavra apaga necessariamente as outras) $\mathrm{e}$

b2) o silêncio local, que refere à censura propriamente, compreendida como aquilo que é proibido dizer em uma certa conjuntura, ou melhor, a interdição para um sujeito de circular por certas regiões de sentidos e, portanto, por certas regiões de constituição de sua identidade (ORLANDI, 1996, p.463).

Essas reflexões de Orlandi sobre o silêncio remetem a questões extremamente relevantes para a Análise de Discurso, a exemplo da política do silêncio ou silenciamento, que significa "tomar" a palavra, fazer calar, obrigar a dizer etc. $\mathrm{O}$ silêncio pode ser considerado como parte tanto da retórica da dominação como da retórica do oprimido. Dessa forma, não é suficiente pensar o silenciamento. Para compreender a linguagem é preciso compreender o silêncio para além da sua dimensão política.

Por isso, o silêncio é fundamental, ou seja, ele[...] "é a matéria significante por excelência. $\mathrm{O}$ real da significação é o silêncio [...] o silêncio é o real do discurso" (ORLANDI, 1997, p.31).

Nesse contexto, o homem está fadado a significar diante do mundo, com ou sem palavras, pois ele está fatalmente constituído pela sua relação com o simbólico. 
Interessante perceber a tendência em nossas formas sociais do "império do verbal", traduzindo-se o silêncio em linguagem. Dessa maneira, percebe-se o silêncio como linguagem e o mesmo perde sua especificidade como matéria significante diferente da linguagem. Nessa perspectiva, pensa-se o silêncio como falta e a autora propõe pensar a linguagem como excesso. A linguagem aparece como "figura" e o silêncio como "fundo". Orlandi, ao inverter essa posição, demonstra o silêncio como "figura" na medida em que ele é fundante. Assim, constitutivo em primeiras e múltiplas instâncias, o silêncio tem prioridade sobre as palavras. A linguagem por sua vez é categorização do silêncio.

A linguagem é a conjugação significante da existência e é produzida pelo homem, para domesticar a significação. A fala divide o silêncio. Organiza-o. O silêncio é disperso, e a fala é voltada para a unicidade e as entidades discretas. Formas. Segmentos visíveis e funcionais que tornam a significação calculável. Se tudo isso pode ser dito a propósito da linguagem, falar do silêncio traz em si, uma dificuldade maior, já que ele se apresenta como absoluto, contínuo, disperso. $\mathrm{O}$ silêncio não está disponível à visibilidade, não é diretamente observável. Ele passa pelas palavras. Não dura. Ele escorre por entre as tramas da fala. Para tratar da questão do silêncio, já que é impossível observá-lo (organizá-lo) podemos usar duas ordens de metáfora: a do mar e a do eco. Em ambas jogam a grande extensão e um certo movimento que retorna e, ao mesmo tempo, produz um deslocamento. O final da onda que o mar sempre adia. O mar: incalculável, disperso, profundo, imóvel em seu movimento monótono, do qual as ondas são as frestas, que o tornam visível. Imagem. O eco: repetição, não-finito, movimento contínuo. Também fresta para ouvi-lo. Som. [...] Como para o mar, é na profundidade, no silêncio, que está o real do sentido (ORLANDI, 1997, p.35).

O silêncio enquanto espaço diferencial que permite a linguagem significar é também a instância em que se produz o movimento, pois nele o sentido se faz em seu caminho, a palavra segue o seu percurso e o sujeito realiza a relação de sua identidade e diferença. Portanto, é o silêncio um dos componentes da relação do sujeito com as formas discursivas, que permite ao sujeito percorrer formações discursivas diferentes, a não ser que haja intervenção da censura. Assim, como o 
sentido é errático o sujeito é itinerante, pois perpassa e é perpassado pela diferença como habita e é habitado por muitas formações discursivas. O que vai mantê-lo em sua identidade é seu estar em silêncio, pois antes de ser palavra todo sentido já foi silêncio, isto é, todo sentido já se dispôs antes em silêncio na relação com o sujeito.

Para fazer-nos entender o silêncio, Orlandi propõe um distanciamento dos modelos existentes ou de "tendências integracionistas, como a pragmática, a etnometodologia, as teorias da enunciação que reduzem o silêncio à linguagem verbal". Sendo assim, pensar o silêncio significa coragem contra a hegemonia do formalismo, do positivismo, porque aí ele está excluído pelo seu caráter não-visível (legível), obscuro, contínuo, não calculável.

Para a autora, o silêncio não é diretamente observável, entretanto ele não é vazio nem mesmo do ponto de vista da percepção: "nós o sentimos, ele está lá" e para torná-lo visível é preciso observá-lo indiretamente através de métodos (discursivos), históricos, críticos e des-construtivistas, pois sem teoria é impossível atingir o seu modo de existência e funcionamento na significação.

\begin{abstract}
Discursivamente, o sentido se faz em todas as direções. Conceitos discursivos como 'interdiscurso' (memória do dizer), 'intertexto' (relação entre textos), 'relação de sentidos', o atestam. A significação não se desenvolve sobre uma linha reta, mensurável, calculável, segmentável. Os sentidos são dispersos, eles se desenvolvem em todas as direções e se fazem por diferentes matérias, entre as quais se encontra o silêncio. A materialidade do sentido não é indiferente aos processos de significação e a seus efeitos: o silêncio significa de modo contínuo, absoluto, enquanto que a linguagem verbal significa por unidades discretas, formais. Eis uma diferença que é preciso não apagar (ORLANDI, 1997, p.48).
\end{abstract}

A dificuldade na análise da questão silêncio é a necessidade de uma ruptura com paradigmas que colocam a linguagem como centro para o qual se orientam tanto a significação do silêncio quanto a sua explicação.

A autora aponta que o silêncio é observado indiretamente. Para isso, mais do que "marcas" (paradigma da demonstração), existem "pis- 
tas" (conjecturas) e para analisar o silêncio é preciso fazer intervir a teoria enquanto crítica.

Em conseqüência, é preciso se deslocar a análise do domínio dos produtos para o dos processos de produção dos sentidos. $O$ método de que necessitamos deve então ser 'histórico' (discursivo) e fazer apelo à 'interdiscursividade', trabalhando com os entremeios, os reflexos indiretos, os efeitos (ORLANDI, 1997, p.57).

Por não suportar o silêncio o homem lhe permite apenas uma existência efêmera. É através da relação entre diversos fragmentos da linguagem que é possível construir uma certa duração para poder observá-lo e nas condições em que ele se produz. É a historicidade inscrita que pode torná-lo compreensível.

Orlandi (1997) fala do silêncio como sentido, história, como matéria significante. Não interessa o silêncio em sua qualidade física, pois ele é o que instala o limiar do sentido.

Assim, o silêncio é condição de significação, resultando na incompletude constitutiva da linguagem. A busca da completude implicaria na ausência do silêncio.

Também o sujeito tem uma relação com a incompletude. Em face do discurso ele estabelece um laço com o silêncio, mesmo que não seja em um nível completamente consciente. Para falar, o sujeito necessita do silêncio, que é fundamento essencial ao sentido e que ele reinstaura falando.

Para a autora, aí está um dos aspectos da polissemia (o que se pode dizer), pois quanto mais se diz, mais o silêncio se instala, mais os sentidos se tornam possíveis e mais se tem a falar.

A incompletude do sujeito, pode ser explicada pelo esquecimento número 1 de Pêcheux, apesar dos processos discursivos se realizarem pelo sujeito, não têm origem nele. Ao falar o sujeito se divide, ou seja, as suas palavras são necessariamente as palavras dos outros. É aqui que a autora aponta a relação entre identidade e alteridade: 'um movimento ambíguo que distingue (separa) e ao mesmo tempo integra (liga), demarcando o sujeito em sua relação com o outro' (ORLANDI, 1997, p.80). 
A incompletude do sujeito pode, portanto, ser refletida como trabalho do silêncio. Sua relação com ele é sua relação com a divisão e com o múltiplo.

Finalmente, o silêncio é um componente fundamental na relação do sujeito com as formações discursivas, pois permite a constituição da história e não somente como reprodução, mas como transformação dos sentidos.

De onde se pode concluir que há um trabalho silencioso do homem com a realidade que lhe propicia a sua dimensão histórica, já que mesmo o silêncio é sentido. O que nos leva a concluir que não se pode estar fora do sentido assim como, não se pode estar fora da história (ORLANDI, 1997, p.94).

Assim, as condições de produção incluem essencialmente os sujeitos e a situação, mas também a memória faz parte da produção do discurso. Segundo Orlandi (1999, p.31), a maneira como a memória faz movimentar as condições de produção é de suma importância. Quando pensada em relação ao discurso é discutida como interdiscurso, já que este é definido como aquilo que fala antes, em outro lugar e independentemente, isto é, memória discursiva: o saber discursivo que torna possível todo dizer é que retorna sob a forma do pré-construído, o jádito que está na base do dizível, sustentando cada tomada da palavra. Esse já-dito que apóia a possibilidade de todo o dizer é fundamental para a compreensão do funcionamento do discurso, da sua relação com os sujeitos e com a ideologia.

Há, portanto, uma relação entre o já-dito e o que se está dizendo, o que existe entre o interdiscurso e o intradiscurso. Valendo-se da reflexão de Courtine (1984), Orlandi mostra como o autor desenvolve a diferença considerando a constituição, representando o interdiscurso em um eixo vertical em que possuiríamos todos os dizeres já-ditos e esquecidos em uma estratificação de enunciados que, em seu conjunto, representam o dizível. No eixo horizontal, o intradiscurso, o eixo da formulação, ou seja, o que estamos dizendo naquele momento dado, em condições dadas.

Desse modo, todo dizer se encontra na confluência dos dois eixos: o da memória, que é a constituição e o da atualidade, que é a formulação. 
Para compreender como a história, enquanto memória9 ${ }^{9}$ se faz presente no discurso é necessária a análise das formas de inscrição da historicidade ou de uma formação social em uma dada conjuntura na linguagem: É possível entrever os processos discursivos que atuam com durabilidade e cristalização de determinados sentidos em detrimento de outros.

Orlandi (1993) alerta para o fato de que não basta apenas atribuir à memória o espaço da reprodução homogênea de determinados sentidos que são produzidos por formações hegemônicas em dado período, mas também é importante considerar a ocorrência de um "silenciamento" temporário de sentidos excluídos. A memória é, portanto, constituída por falhas, lacunas, que são repletas de historicidade.

Para Mariani (1998, p.41), trabalhar com a memória discursiva é "estar observando retomadas e/ou disjunções nada específicas, uma vez que se trata de conflitos pela regularização e hegemonia de sentidos".

Assim, a autora atenta para as seguintes considerações: a ocorrência do acontecimento provoca produção de sentidos e não significa falar da existência de sentidos inteiramente disponíveis, isto é, prontos para serem colados aos acontecimentos; alguns dos efeitos da memória são a ilusão da completude e da existência concreta de uma realidade passada.

'Para se falar de memória, em síntese, é necessário se falar do processo de construção dos sentidos e dos efeitos de realidade que eles produzem, isto é, da ilusão referencial' (ORLANDI, 1999). Melhor dizendo, mexer com a memória é compreender o imaginário e desautomatizar seus efeitos. Ao mesmo tempo, os sentidos se formam na história, supondo-se, exatamente, o trabalho de memória. É necessário ter em mente, também, que para a $\mathrm{AD}$ interessa investigar o papel da linguagem nestes processos, buscando entender, em termos da materialidade da língua, o jogo das repetições, diferenças, deslocamentos, transformações por que passam os sentidos. Em outras palavras, a $\mathrm{AD}$ 'se dá

\footnotetext{
${ }^{9}$ Para a $\mathrm{AD}$, a noção de memória [...] diz respeito à existência histórica do enunciado no interior de práticas discursivas reguladas por aparelhos ideológicos: como outros enunciados estão na origem de atos novos, como são retomados ou transformados, qual a força de sua permanência (BRANDÃO, 1998, p.128).
} 
precisamente com o objetivo de explicitar e descrever montagens, arranjos sócio-históricos de constelações de enunciados' (PÊCHEUX, apud MARIANI, 1998, p.44).

É assim que a $\mathrm{AD}$, ao apontar a opacidade da linguagem alerta para o fato de que se ela não for desvendada de antemão, o discurso só ilustrará uma história já dada pelo analista. Se o dizer só é possível através do silenciamento de outros dizeres, é nas lacunas instauradas pelo silêncio que estão os sentidos e é trabalhando nelas que o pesquisador consegue, pelo menos em parte, desvendar o real (se é que ele existe).

$\mathrm{A} \mathrm{AD}$ não se restringe ao domínio da lingüística porquanto o conceito de discurso é o que desloca a noção da linguagem, enquanto informação, e propõe considerar o discurso como efeito de sentidos entre locutores. O que conta não são os falantes como tais, mas as inagens de seus lugares, isto é, são as formações imaginárias, que presidem o discurso.

$\mathrm{A} \mathrm{AD}$ produz uma mudança ao orientar que a problemática opacidade da linguagem não deve ser eliminada, mas compreendida e utilizada no domínio das Ciências Sociais. É só através da teoria que o analista, relacionando criticamente com sua posição, compreende. Produzir uma leitura simplesmente a partir de sua posição, apenas reflete sua posição de leitor na leitura que produz. Compreender significa saber que o sentido poderia ser outro, por isso a $A D$, apesar de também ser interpretativa, não é simplesmente um método de interpretação, pois não confere nenhum sentido ao texto. Ela problematiza a relação com o texto na tentativa de explicitar os processos de significação que nele estão configurados, os mecanismos de produção de sentidos que estão funcionando. 


\section{Referências}

AUTHIER-REVUZ, J. Falta do dizer, dizer da fala: as palavras do silêncio. In: ORLANDI, E. P. Gestos de leitura: da História no Discurso. Campinas: UNICAMP, 1997.

BRANDÃO, H. H. N. Introdução à análise do discurso. Campinas: UNICAMP, 1991.

. Subjetividade, argumentação, polifonia: a propaganda da Petrobrás. São Paulo: UNESP, 1998.

DUCROT, O. Nota sobre a pressuposição e o sentido literal. In: HENRY, Paul. A ferramenta imperfeita: língua, sujeito e discurso. Campinas: UNICAMP, 1992.

GUIMARÃES, E. Independência e morte. In: ORLANDI, E. P. (Org.). Discurso fundador: a formação do país e a construção da identidade nacional. Campinas: Pontes, 1993.

- Os limites do sentido: um estudo histórico e enunciativo da linguagem. Campinas : Pontes, 1995.

HENRY, P. Os fundamentos teóricos da "Análise automática do discurso" de Michel Pêcheux. In: GADET, T.; HAK, T. (Orgs.) Por uma análise automática do discurso: uma introdução à obra de Michel Pêcheux. Campinas: UNICAMP, 1992.

MARIANI, B. OPCB e a imprensa: os comunistas no imaginário dos jornais (1922 - 1989). Campinas: UNICAMP, 1998.

ORLANDI, E. P. Discurso fundador: a formaçãe, do país e a construção da identidade nacional. Campinas: Pontes, 1993.

. Efeitos do verbal sobre o não verbal. In: Magalhães, I. (Org.) As múltiplas faces da linguagem. Brasilia : Ed. UNB, 1996.

_. As formas do silêncio: no movimento dos sentidos. Campinas: UNICAMP, 1997.

1999.

Análise do discurso: princípios e procedimentos. Campinas: Pontes,

PÊCHEUX, M. A análise de discurso: três épocas (1983). In: GADET, T.; HAK, T. (Orgs.) Por uma análise automática do discurso: uma introdução à obra de Michel Pêchex. Campinas: UNICAMP, 1997. 
PÊCHEUX, M; FUCHS, C. A propósito da análise automática do discurso: atualização e perspectiva. In: GADET, T.; HAK, T. (Orgs.) Por uma análise automática do discurso: uma introdução à obra de Michel Pêchex. Campinas: UNICAMP, 1997.

Semântica e discurso: uma crítica à afirmação do b́bvio. Campinas: UNICAMP, $1997 \mathrm{a}$.

. O discurso: estrutura ou acontecimento. Campinas: Pontes, $1997 \mathrm{~b}$. POSSENTI, S. O sujeito fora do arquivo. In: MAGALHÃES, Izabel (org.). As múltiplas faces da linguagem. Brasília: UNB, 1996.

\section{Abstract}

The Discourse Analysis (DA) by Michel Pêcheux has as a main project to establish the discourse process as a material product of internal and external relations, that is, the linguistic grounding and the ideological determination, respectively. The purpose of this work is to how the issue of the determination of meaning as well as of the subject's ideological constitution in language is dealt with the discourse practice in an interdisciplinary scope.

Key words: discourse analysis, meanings, silence. 